\title{
Análise da herança da resistência a Puccinia psidii em progênies de híbridos interespecíficos de eucalipto avaliadas sob condições naturais de infecção
}

\author{
Juliana E.C. Teixeira ${ }^{1 *}$, Fernanda T.P. Guedes ${ }^{3}$, Donizete C. Dias ${ }^{2}$, César A.V. Bonine ${ }^{2} \&$ Luis Eduardo A. \\ Camargo $^{3}$
}

${ }^{1}$ Departamento de Genética, Universidade de São Paulo, ESALQ, 13.418-900, Piracicaba, SP, Brasil; ${ }^{2}$ Votorantim Celulose e Papel - VCP, Unidade Florestal Jacareí, Centro de Pesquisa e Desenvolvimento Florestal, 12.340-010, Jacareí, SP, Brasil; ${ }^{3}$ Departamento de Entomologia, Fitopatologia e Zoologia Agrícola, Universidade de São Paulo, ESALQ, 13.418-900, Piracicaba, SP, Brasil

Autor para correspondência: Luis Eduardo A. Camargo, e-mail: leacamar@esalq.usp.br

\section{RESUMO}

A ferrugem, causada pelo fungo Puccinia psidii, é atualmente a mais importante doença do eucalipto. Esta doença está amplamente disseminada pelo Brasil e causa sérios danos em viveiros e plantações. A identificação de germoplasma resistente aliado ao conhecimento da base genética da resistência são os requerimentos primordiais para o sucesso de programas de melhoramento visando à produção de cultivares resistentes. Estudos anteriores sobre a herança da resistência em condições controladas sugerem tanto uma herança monogênica como a participação de pelo menos 2 genes conferindo resistência à doença. O objetivo deste estudo foi avaliar a resistência a $P$. psidii, em condições de campo em quatorze progênies obtidas a partir de cruzamentos e auto-cruzamentos controlados entre quatro clones híbridos de Eucalyptus grandis Hill ex Maiden x Eucalyptus urophylla ST Blake, que contrastam para a resistência ao fungo. Os resultados indicam que a resistência pode ser explicada por um loco com efeito principal e pelo menos três alelos diferentes, com interações entre os alelos, resultando no fenótipo de resistência ou suscetibilidade. Entretanto, locos com menor efeito devem influenciar a resistência, uma vez que foram observadas variações nas classes de severidade da escala utilizada. Nenhuma diferença na segregação para a resistência foi observada entre cruzamentos recíprocos, sugerindo que não existe influência citoplasmática no controle deste caráter.

Palavras chave: Eucalyptus, Uredinales, ferrugem, resistência genética.

\begin{abstract}
Inheritance of resistance to Puccinia psidii G. Winter in a eucalyptus interspecific hybrid progeny evaluated under conditions of natural infection

Rust caused by the fungus Puccinia psidii is currently the most important disease of eucalyptus. It is widely disseminated in Brazil, and causes serious damage in nurseries and plantation areas. The identification of resistant germplasm along with knowledge of the genetic basis of resistance heredity are the first requirements for the success of breeding programs aiming to develop resistant varieties. Earlier studies carried out under controlled conditions suggested a monogenic control as well as the participation of at least two genes promoting resistance to rust. The goal of this study was to evaluate the resistance to $P$. psidii under field conditions in fourteen progenies from controlled crosses and self-crosses among four hybrid clones of Eucalyptus grandis Hill ex Maiden x Eucalyptus urophylla ST Blake that contrast for resistance to the fungus. Results indicated that resistance could be explained by one locus with main effects and at least three different alleles. However, loci with minor effects may influence the resistance, since variation on severity classes was observed. Differences in segregation of resistance between reciprocal crosses were not observed, indicating absence of cytoplasmic effects.
\end{abstract}

Keywords: Eucalyptus, Uredinales, rust, disease resistance.

\section{INTRODUÇÃO}

Dentre as várias doenças descritas em eucalipto, a ferrugem, causada pelo fungo Puccinia psidii G. Winter,

\footnotetext{
Parte da tese do primeiro autor. Universidade de São Paulo, ESALQ. Piracicaba SP. 2009.

*Endereço atual: Votorantim Celulose e Papel - VCP, Unidade Florestal Jacareí, Centro de Pesquisa e Desenvolvimento Florestal, 12.340-010, Jacareí, SP.
}

é atualmente uma das mais preocupantes, pois está amplamente disseminada pelo país e causa sérios prejuízos em viveiros e plantios comerciais (Alfenas et al., 2004). Levantamentos efetuados nas regiões do Vale do Paraíba e sul do estado de São Paulo revelaram incidências de até $35 \%$ de árvores doentes em plantios de Eucalyptus grandis Hill ex Maiden, com idade em torno de 6 meses. Plantas infectadas apresentaram reduções médias entre $25-35 \%$ em altura e diâmetro, quando comparadas com plantas sadias (Silveira et al., 1998, citado por Silveira \& Higashi, 2003). 
A primeira descrição deste fungo no Brasil ocorreu em mudas de goiabeira e em eucalipto foi relatado primeiramente em Eucalyptus citriodora, hoje Corymbia citriodora (Hook.) Hill \& Johnson, em 1944 (Coutinho et al., 1998). A primeira epidemia relevante de P. psidii em eucalipto ocorreu em 1973 no Espírito Santo, aonde cerca de 400.000 mudas de E. grandis oriundas de sementes vindas da África do Sul foram refugadas em decorrência da doença (Ferreira, 1983). Daí em diante, observou-se várias epidemias, principalmente no Estado de São Paulo (Silveira et al., 1998, citado por Silveira e Higashi, 2003).

P. psidii é nativo da América do Sul e Central e parasita vários gêneros silvestres ou exóticos da família Myrtaceae (Coutinho et al., 1998). Existem relatos deste fungo causando doença em várias mirtáceas na Argentina, Colômbia, Equador, Paraguai, Uruguai, Venezuela, América Central e Flórida (Coutinho et al., 1998). Em eucalipto, já foi relatada nas espécies E. grandis, E. urophylla, E. nitens, E. phaeotricha, C. citriodora, E. cloeziana, E. obliqua, E. pilularis, E. saligna (Coutinho et al., 1998) e mais recentemente em E. globulus (Telechea et al., 2003). A ferrugem é considerada uma doença quarentenária de alto risco de introdução na Austrália e África do Sul, em vista da ampla gama de hospedeiros na família Myrtaceae presente nestes países (Glen et al., 2007).

A ferrugem do eucalipto provavelmente é causada pelos mesmos genótipos que infectavam mirtáceas nativas, haja vista que estudos de inoculação cruzada com isolados monopustulares oriundos de Eucalyptus spp., Psidium guajava e Syzygiumjambos apóiam esta hipótese. Adescrição de raças ou formae specialis para Puccinia psidii ainda não foi relatada como ocorre para outras espécies do gênero, no entanto, há indícios de que existe especialização fisiológica dentro de P. psidii (Xavier et al., 2002; Aparecido et al., 2003; Furtado et al., 2005) e a superação da resistência em clones de eucalipto tem sido observada em vários plantios de empresas privadas (Puccinia psidii pode ser facilmente identificada através de seus sinais, na forma de grande esporulação urediniospórica, pulverulenta e de coloração amarela em órgãos jovens da planta, como primórdios foliares, pecíolos, terminais de galhos ou caules ainda em desenvolvimento. Em folhas mais novas, a esporulação ocorre em ambas as faces do limbo, embora com maior intensidade na face abaxial. Em materiais altamente suscetíveis, as pústulas podem coalescer e recobrir a superfície das brotações, causando deformações, perda da dominância apical, diminuição do crescimento e, eventualmente, a morte da planta. Estes sintomas podem ser observados em touças ou mudas no viveiro, em plantas no campo com até dois anos de idade e em brotações após o corte raso (Ferreira 1983; Alfenas et al., 2004).

Devido à ampla variabilidade genética inter e intraespecífica, a forma mais empregada de controle do patógeno é a utilização de materiais resistentes ou com rápido crescimento, neste caso para que as plantas fiquem menos tempo expostas ao patógeno, já que acima de 2 a $3 \mathrm{~m}$ de altura o microclima não é favorável ao desenvolvimento da doença (Alfenas et al., 2004; Zauza, 2007). Existem fungicidas capazes de controlar o desenvolvimento do fungo, porém, esta é uma medida utilizada apenas em jardins clonais devido aos altos custos (Alfenas et al., 2004).

$\mathrm{Na}$ literatura, são encontrados diversos trabalhos sobre resistência genética a ferrugem (Dianese et al., 1986; Carvalho et al., 1998). Entretanto, estes trabalhos estão focados, especialmente, na seleção de procedências e progênies por meio de inoculações artificiais ou infecções naturais do patógeno. Poucos estudos abordaram a herança da resistência ao patógeno (Junghans et al., 2003b; Rosado, 2007; Alves, 2008). Junghans et al. (2003b), relataram que a resistência à ferrugem em E. grandis em condições controladas de infecção, é devido a um gene dominante, denominado $\operatorname{Pprl}(P$. psidii resistance gene 1), de penetrância incompleta e dependente do "background" genético. Aparentemente, em alguns genótipos a resistência está associada a uma aparente resposta de hipersensibilidade, uma vez que em materiais resistentes visualiza-se necrose das células localizadas no sitio de penetração do patógeno (Junghans et al., 2003a; Xavier, 2002).

Um padrão de herança diferente de um controle monogênico foi descrito por Rosado Rosado (2007) e Alves (2008). Os autores trabalharam com diferentes progênies de cruzamentos interespecíficos de Eucalyptus e observaram um padrão de herança complexo, com distorções de segregação e que discordam dos resultados encontrados em Junghans et al. (2003b). Porém, fatores como pequeno tamanho das progênies, utilização de híbridos interespecíficos, baixa concentração de inóculo e falta de controle das condições ambientais necessárias à infecção podem contribuir para a avaliação equivocada de clones e colaborar para distorções de segregação (Rosado, 2007). Este trabalho tem como objetivo avaliar a resistência à ferrugem sob condições de campo, utilizando progênies oriundas do cruzamento inter-específicos entre clones resistentes e suscetíveis e auto-fecundações destes materiais genéticos.

\section{MATERIAL E MÉTODOS}

\section{Material Vegetal}

Quatorze progênies, inicialmente com120 plantas cada, foram obtidas a partir de cruzamentos e autocruzamentos controlados realizados em 2005 por técnicos do programa de melhoramento da Votorantim Celulose e Papel - VCP. Neste esquema de cruzamentos, os cruzamentos recíprocos também foram realizados. Os quatro genitores das progênies (denominados V1, V2, V3 e V4) são híbridos interespecíficos de E. grandis $\mathrm{x}$ E. urophylla e contrastam para a resistência a ferrugem. Os clones V1 e V4 são suscetíveis, classificados como S3 e S2, respectivamente, e os clones V2 e V3 são resistentes, classificados respectivamente como $\mathrm{S} 0$ e $\mathrm{S} 1$, segundo critério de classificação proposto por Junghans et al. (2003a). As 
progênies foram avaliadas para reação à infecção natural por P. psidii e utilizadas para estudo de herança da resistência.

\section{Avaliação da resistência a Puccinia psidii}

As quatorze progênies foram avaliadas para resistência a $P$. psidii em dois ambientes de ocorrência natural de ferrugem, comumente utilizados no programa de melhoramento da empresa como "campos de prova de ferrugem" para seleção de genótipos resistentes. Os campos estão localizados nos municípios de Itapetininga e Santa Branca, ambos no Estado de São Paulo. O delineamento experimental foi o de blocos ao acaso, com parcelas lineares de 10 plantas e 6 repetições. Os quatro genitores foram incluídos como tratamentos testemunha. Bordaduras externas com o genitor suscetível V1 foram utilizadas para aumentar e homogeneizar a distribuição do inóculo nas áreas experimentais.

Todos os experimentos foram instalados entre novembro e dezembro de 2005 e quatro avaliações da severidade da doença foram realizadas no primeiro semestre de 2006, aproximadamente aos 90,120,150 e 180 dias após o plantio. A avaliação foi baseada em uma escala de notas de quatro níveis de severidade adaptada por melhoristas do setor florestal e utilizada por Zamprogno et al. (2008) (Figura 1): Nota 0: planta com ausência de esporulação ou planta com necrose, semelhante a reação de hipersensibilidade; Nota 1: planta com poucas pústulas, com esporulações, geralmente espaçadas ou apenas ocasionalmente abundantes nos limbos de folhas novas; Nota 2: planta com pústulas com esporulação abundante nos limbos foliares, folhas novas e pecíolos de folhas mais novas; Nota 3: planta com pústulas com esporulação intensa no limbo foliar de folhas novas, pecíolos de folhas novas, nos terminais de galhos e haste principal, comprometendo a dominância apical e estrutura foliar da planta.

Plantas com notas N0 e N1 foram consideradas resistentes e plantas com notas N2 e N3 suscetíveis. Este critério foi adotado levando-se em conta que sintomas do tipo N1 não comprometem o crescimento e desenvolvimento da planta em campo, o que não ocorre com plantas com sintomas $\mathrm{N} 2$ e N3, que podem evoluir para a perda da dominância apical e comprometimento da estrutura da planta, afetando seu crescimento e desenvolvimento. Este critério tem sido usado em rotina na seleção de genótipos resistentes no programa de melhoramento da VCP.

\section{Herança da resistência}

Hipóteses de segregação mendeliana da resistência foram formuladas e as razões de segregação esperadas, associadas a cada hipótese, foram comparadas com as segregações observadas por meio de teste de qui-quadrado em níveis de $5 \%$ e $1 \%$ de probabilidade. Os dados foram corrigidos utilizando a correção de Yates e submetidos ao teste de heterogeneidade do qui-quadrado (Zar, 1996) visando confirmar se a análise de qui-quadrado utilizando os dados obtidos nos dois experimentos e agrupados para cada progênie poderia ser utilizada.

\section{RESULTADOS E DISCUSSÃO}

Progênies de irmãos-completos foram obtidas a partir de cruzamentos e autofecundações entre 4 genitores classificados como resistentes ou suscetíveis com base em resultados de inoculações artificiais realizadas anteriormente. A natureza resistente ou suscetível dos genitores foi confirmada no presente estudo em dois locais distintos, escolhidos por serem locais de ocorrências naturais de epidemias de ferrugem em anos anteriores.

Todas as plantas foram avaliadas quatro vezes e algumas podem ter recebido notas diferentes entre avaliações. Nestes casos, considerou-se a maior nota para efeito de classificação final dentro dos quatro níveis de severidade. Este critério foi adotado para garantir que plantas classificadas com notas N2 ou N3 em dada avaliação e que apresentaram notas $\mathrm{N} 0$ ou N1 em avaliações subseqüentes fossem erroneamente classificadas como resistentes. Isto, pois, como as avaliações representam momentos pontuais da epidemia, é possível que no momento de uma das avaliações, uma determinada planta suscetível pode não ter apresentado sintomas em dada avaliação, pois esta pode ter coincidido com o momento de lançamento de novas folhas.

Os níveis de severidade de ferrugem verificados nos dois experimentos foram elevados e permitiram a distinção de genótipos resistentes e suscetíveis (Tabela 1; Figuras 2 e 3). Verificou-se um aumento da severidade de cada planta ao longo das avaliações. Um maior número de plantas cujos níveis de severidade foram os mais altos foi observado em Santa Branca SP (Figuras 2 e 3). Como os dados fenotípicos de cada progênie dos dois experimentos foram testados contra a mesma hipótese nula e as amostras pertencem à mesma população, os valores de qui-quadrado de cada progênie foram obtidos através da soma dos valores observados nos dois experimentos (Tabela 1).

Todas as progênies segregaram para resistência a ferrugem, sendo que todas as progênies oriundas do cruzamento entre genitores resistentes ou da autofecundação destes (progênies 1, 2, 4 e 5) segregaram na proporção de 3 resistentes para 1 suscetível (Tabela 1). Já progênies oriundas da autofecundação ou do cruzamento entre genitores suscetíveis segregaram na proporção de 3 suscetíveis para 1 resistente (progênies 10, 11 e 14). Em progênies oriundas de cruzamentos entre genitores resistentes e suscetíveis, a segregação observada foi de 1 resistente para 1 suscetível (progênies 3, 6, 7, 8, 9, 12 e 13). Estes resultados indicaram tanto controle monogênico da resistência como que todos os genitores são heterozigóticos para o loco de resistência. Nenhuma diferença significativa na segregação para a resistência foi observada entre cruzamentos recíprocos, sugerindo que não existe influência citoplasmática no controle deste caráter (Tabela 1). 


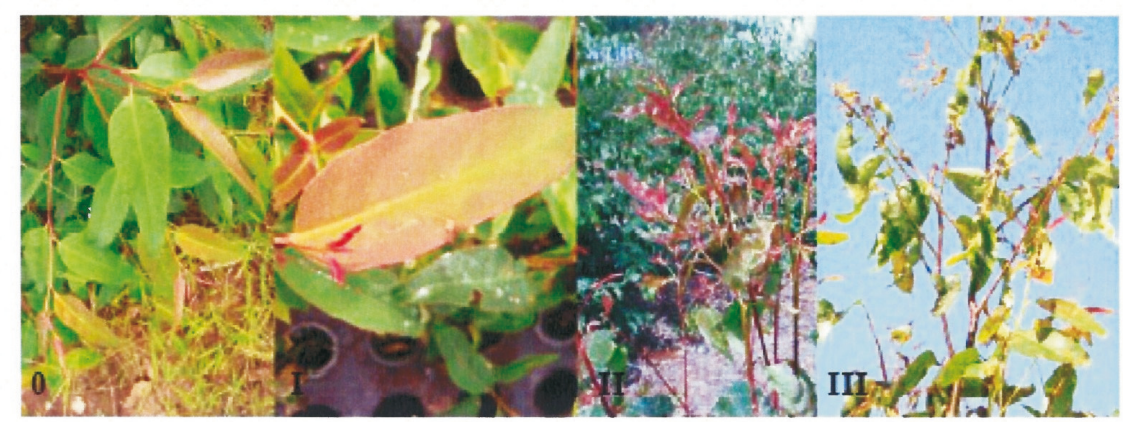

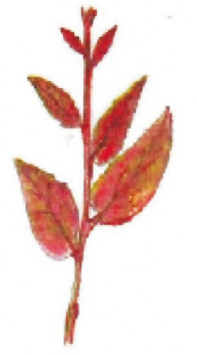

0

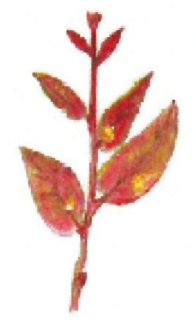

I

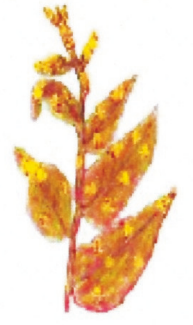

II

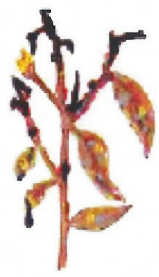

III

FIGURA 1 - Escala de notas utilizada para avaliação da severidade de ferrugem.

TABELA 1 - Distribuição de plantas em classes de severidade e proporção esperada entre plantas resistentes e suscetíveis assumindo modelo de herança monogênica em 14 progênies F1 avaliadas, sob condição de campo em Santa Branca e Itapetininga SP. 2006

\begin{tabular}{|c|c|c|c|c|c|c|c|c|}
\hline \multirow[t]{2}{*}{ Progênie } & \multicolumn{5}{|c|}{ Número de Plantas/Classe de Severidade } & \multirow{2}{*}{\multicolumn{2}{|c|}{$\begin{array}{c}\text { Proporção } \\
\text { Esperada } \\
\text { R:S a }\end{array}$}} & \multirow[t]{2}{*}{$\mathbf{X}^{2}$} \\
\hline & No & N1 & $\mathbf{N 2}$ & N3 & $\mathbf{R}$ & & & \\
\hline Progênie 1 V2xV2 & 31 & 64 & 20 & 2 & 95 & 22 & $3: 1$ & $2,08^{\mathrm{ns}}$ \\
\hline Progênie 2 V2xV3 & 14 & 67 & 30 & 5 & 81 & 35 & $3: 1$ & $1,39^{\mathrm{ns}}$ \\
\hline Progênie 3 V2xV4 & 14 & 45 & 36 & 23 & 59 & 59 & $1: 1$ & $0,00^{\text {ns }}$ \\
\hline Progênie 4 V3xV2 & 24 & 49 & 32 & 11 & 73 & 43 & $3: 1$ & $8,70 *$ \\
\hline Progênie 5 V3xV3 & 20 & 68 & 24 & 0 & 88 & 24 & $3: 1$ & $0,58^{\text {ns }}$ \\
\hline Progênie 6 V3xV4 & 11 & 60 & 34 & 12 & 71 & 46 & $1: 1$ & $4,92^{n s^{*}}$ \\
\hline Progênie 7 V3xV1 & 5 & 45 & 53 & 11 & 50 & 64 & $1: 1$ & $1,48^{\mathrm{ns}}$ \\
\hline Progênie 8 V4xV2 & 8 & 50 & 33 & 27 & 58 & 60 & $1: 1$ & $0,08^{\mathrm{ns}}$ \\
\hline Progênie 9 V4xV3 & 5 & 48 & 54 & 12 & 53 & 66 & $1: 1$ & $1,21 \mathrm{~ns}$ \\
\hline Progênie $10 \mathrm{~V} 4 \mathrm{xV} 4$ & 3 & 22 & 59 & 32 & 25 & 91 & $1: 3$ & $0,56^{\mathrm{ns}}$ \\
\hline Progênie 11 V4xV1 & 0 & 14 & 54 & 50 & 14 & 104 & $1: 3$ & $10,17 *$ \\
\hline Progênie 12 V1xV2 & 16 & 41 & 42 & 20 & 57 & 62 & $1: 1$ & $0,13^{\mathrm{ns}}$ \\
\hline Progênie $13 \mathrm{~V} 1 \mathrm{xV} 3$ & 13 & 54 & 36 & 16 & 67 & 52 & $1: 1$ & $1,65^{\mathrm{ns}}$ \\
\hline Progênie 14 V1xV4 & 0 & 33 & 60 & 25 & 33 & 85 & $1: 3$ & $0,41^{\text {ns }}$ \\
\hline
\end{tabular}

${ }^{a} \mathrm{~A}$ razão resistente:suscetível (R:S) é baseada em $\mathrm{R}=\mathrm{N} 0+\mathrm{N} 1$ e $\mathrm{S}=\mathrm{N} 2+\mathrm{N} 3$. Hipótese de herança monogênica.

${ }^{\text {ns }}$ Não significativo em nível de $5 \%$ de probabilidade e ${ }^{\text {ns* }}$ não significativo em nível de $1 \%$ de probabilidade pelo teste de qui-quadrado. 


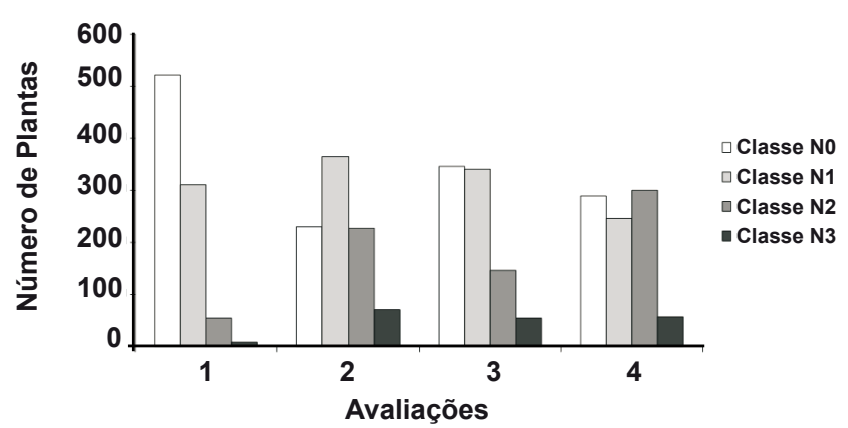

FIGURA 2 - Distribuição das plantas de todas as progênies classificadas dentro das quatro classes de severidade nas 4 avaliações realizadas em Santa Branca SP. 2006.

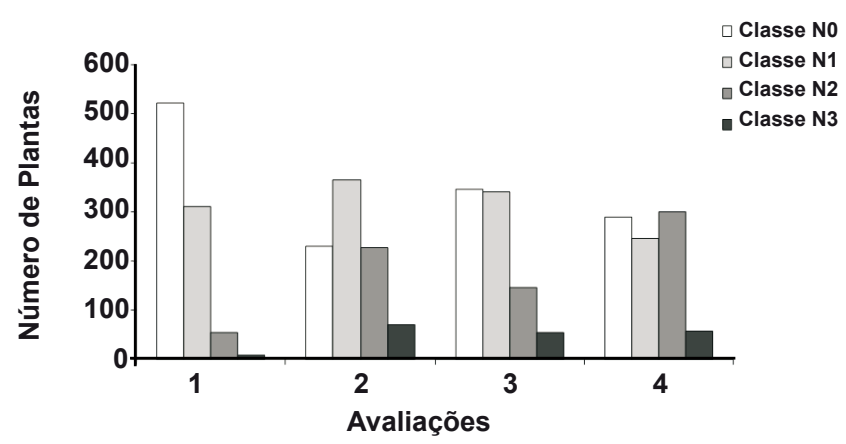

FIGURA 3 - Distribuição das plantas de todas as progênies classificadas dentro das quatro classes de severidade nas 4 avaliações realizadas em Itapetininga SP. 2006.

Apenas as progênies 4 e 11 apresentaram valores que não se ajustaram à hipótese de herança monogênica. No entanto, quando analisamos a segregação nas duas progênies em cada experimento individualmente, observouse que os padrões de segregação na progênie 4 nos dois experimentos e na progênie 11 avaliada em Santa Branca SP se ajustaram à hipótese de herança monogênica (Tabela 2). Apenas a progênie 11, oriunda do cruzamento entre os dois genitores suscetíveis (V1 e V4), quando avaliada em Itapetininga/SP, não apresentou um resultado que pudesse ser explicado pelo modelo de herança monogênica em nível de 5 ou $1 \%$ de probabilidade.

Os resultados da progênie 11 avaliada em Itapetininga SP estão muito próximos da não significância. Uma vezque as condições ambientais foram favoráveis ao desenvolvimento da doença, explicações para este fato podem ter origem no acaso, durante a escolha aleatória dos indivíduos da progênie que foram usados nos experimentos.

$\mathrm{O}$ modo de herança da resistência à ferrugem relatado neste trabalho concorda com resultados de trabalhos realizados sob condições controladas de infecção (Junghans et al., 2003b; Rosado, 2007; Alves, 2008). Segundo estes trabalhos, variações dentro de cada classe fenotípica, principalmente classes N1 e N2, também foram observadas e pode ser um indicativo de que genes de efeitos secundários também participem da resposta de resistência. No entanto, é evidente que um loco de grande efeito é o responsável por grande parte da resistência, a exemplo do já relatado em outros trabalhos com base em análises em progênies de origens diferentes (Junghans et al., 2003b; Bueno et al., 2004; Rosado, 2007; Alves, 2008).

Considerando os padrões de segregação fenotípica em cada progênie, a resistência pode ser explicada por um modelo monogênico com pelo menos 3 alelos $\left(\mathrm{A}^{1}, \mathrm{~A}^{2}\right.$ e $\left.\mathrm{A}^{3}\right)$ seguindo uma série alélica de dominância: $A^{1}>A^{2}>A^{3}$. Neste modelo, os alelos $\mathrm{A}^{1} \mathrm{e} \mathrm{A}^{3}$ conferem resistência à ferrugem e o alelo $\mathrm{A}^{2}$ suscetibilidade. Este modelo foi proposto principalmente baseado nas segregações nas progênies oriundas de autofecundações e cruzamentos entre clones de mesmo fenótipo. Como nas autofecundações de genitores resistentes (V2 e V3) bem como no cruzamento entre eles a segregação encontrada foi de 3 resistentes para 1 suscetível, estes genitores devem possuir os mesmos alelos, um de resistência $\left(\mathrm{A}^{1}\right)$ e um de suscetibilidade, sendo que o alelo de resistência é dominante sobre o de suscetibilidade $\left(\mathrm{A}^{2}\right)$. Considerando os genitores suscetíveis (V1 e V4), como tanto no cruzamento entre eles como na autofecundação de V4, a segregação encontrada foi de 3 suscetíveis para 1 resistente, estes genitores também devem possuir um alelo de resistência e um alelo de suscetibilidade, porém, nestes genitores o alelo de resistência $\left(\mathrm{A}^{3}\right)$ é recessivo em relação ao alelo de suscetibilidade $\left(\mathrm{A}^{2}\right)$. Todas as segregações esperadas para os cruzamentos foram deduzidas (Tabela 3 ).

A maioria dos genes de resistência identificados até o momento possui interação alélica do tipo dominância completa (Bent \& Mackey, 2007), porém em alguns casos alelos recessivos também são encontrados. No patossistema eucalipto-ferrugem, alelos de resistência dominantes e recessivos já foram descritos (Junghans et al., 2003b; Rosado, 2007; Alves, 2008; Zamprogno et al., 2008).

Outros modelos de herança considerando um loco com mais de 3 alelos ou modelos mais complexos, onde a resistência é conferida por mais de um gene, também poderiam explicar estes resultados. Por exemplo, um modelo que considera um loco de resistência bialélico interagindo epistaticamente com outro loco também se aplica aos resultados. Neste modelo, os genitores resistentes seriam $\mathrm{AaBB}$ e os genitores suscetíveis aaBb, sendo que o alelo "A" conferiria resistência e o alelo "a" suscetibilidade. O alelo "b", quando em homozigose na presença do alelo "a", também em homozigose, conferiria resistência ao indivíduo. Modelos mais complexos de herança conferida por dois genes com interações epistáticas têm sido propostos para explicar os resultados de algumas progênies oriundas de cruzamentos interespecíficos (Rosado, 2007; Alves, 2008). No entanto, a hipótese de herança monogênica multialélica é favorecida por ser mais parcimoniosa e pelo fato de que genes de resistência a ferrugens em outras espécies ocorrem 
TABELA 2 - Distribuição de plantas em classes de severidade e proporção esperada entre plantas resistentes e suscetíveis assumindo modelo de herança monogênica das progênies 4 e 11 avaliados, sob condição de campo em Santa Branca e Itapetininga, SP. 2006

\begin{tabular}{|c|c|c|c|c|c|c|c|c|}
\hline \multirow[t]{2}{*}{ Progênie } & \multicolumn{6}{|c|}{ Número de Plantas/Classe de Severidade } & \multirow{2}{*}{$\begin{array}{c}\text { Proporção } \\
\text { Esperada } \\
\text { R:S a } \\
\end{array}$} & \multirow[t]{2}{*}{$X^{2}$} \\
\hline & No & N1 & $\mathbf{V} 2$ & N3 & $\mathbf{R}$ & $\mathbf{S}$ & & \\
\hline Progênie 4/ Itapetininga & 16 & 21 & 19 & 4 & 37 & 23 & $3: 1$ & $5,00 \mathrm{~ns}^{*}$ \\
\hline Progênie 4/ Santa Branca & 8 & 28 & 13 & 7 & 36 & 20 & $3: 1$ & $2,88^{\mathrm{ns}}$ \\
\hline Progênie 11/ Itapetininga & 0 & 5 & 28 & 26 & 5 & 54 & $1: 3$ & $7,73 *$ \\
\hline Progênie 11/ Santa Branca & 0 & 9 & 26 & 24 & 9 & 50 & $1: 3$ & $2,48^{\mathrm{ns}}$ \\
\hline
\end{tabular}

${ }^{a}$ A razão Resistente:Suscetível (R:S) é baseado em R=N0+N1 e S=N2+N3. Hipótese de herança monogênica.

${ }^{\text {ns }}$ Não significativo em nível de $5 \%$ de probabilidade e ${ }^{\text {ns* }}$ não significativo em nível de $1 \%$ de probabilidade pelo teste de qui-quadrado.

TABELA 3 - Cruzamentos e segregações possíveis considerando que a resistência à ferrugem seja controlada por um gene com 3 alelos seguindo a ordem de dominância $\mathrm{A}^{1>} \mathrm{A}^{2}>\mathrm{A}^{3}$

\begin{tabular}{|c|c|c|c|}
\hline & Genótipos & Segregação & Progênie \\
\hline \multirow[t]{4}{*}{$V 1-A^{2} A^{3}$} & $V 1-A^{2} A^{3}$ & 1R:3S & - \\
\hline & $V 2-A^{1} A^{2}$ & 1R:1S & Progênie 12 \\
\hline & V3- $A^{1} A^{2}$ & 1R:1S & Progênie 13 \\
\hline & V4- $A^{2} A^{3}$ & $1 \mathrm{R}: 3 \mathrm{~S}$ & Progênie 14 \\
\hline \multirow[t]{4}{*}{$V 2-A^{1} A^{2}$} & $V 1-A^{2} A^{3}$ & 1R:1S & - \\
\hline & $V 2-A^{1} A^{2}$ & $3 \mathrm{R}: 1 \mathrm{~S}$ & Progênie 1 \\
\hline & V3- $A^{1} A^{2}$ & 3R:1S & Progênie 2 \\
\hline & $V 4-A^{2} A^{3}$ & 1R:1S & Progênie 3 \\
\hline \multirow[t]{4}{*}{$V 3-A^{1} A^{2}$} & $V 1-A^{2} A^{3}$ & 1R:1S & Progênies 7 \\
\hline & $V 2-A^{1} A^{2}$ & 3R:1S & Progênies 4 \\
\hline & $V 3-A^{1} A^{2}$ & 3R:1S & Progênies 5 \\
\hline & $V 4-A^{2} A^{3}$ & 1R:1S & Progênie 6 \\
\hline \multirow[t]{4}{*}{$V 4-A^{2} A^{3}$} & $V 1-A^{2} A^{3}$ & $1 \mathrm{R}: 3 \mathrm{~S}$ & Progênies 11 \\
\hline & V2- $A^{1} A^{2}$ & 1R:1S & Progênies 8 \\
\hline & $V 3-A^{1} A^{2}$ & $1 \mathrm{R}: 1 \mathrm{~S}$ & Progênies 9 \\
\hline & $V 4-A^{2} A^{3}$ & $1 \mathrm{R}: 3 \mathrm{~S}$ & Progênie 10 \\
\hline
\end{tabular}

em séries multialélicas (Buschges et al., 1997). No entanto, a hipótese de multialelismo só poderá ser comprovada após a clonagem destes genes.

A existência de um loco multialélico de resistência a P. psidii em eucalipto é curiosa do ponto de vista evolutivo, já que o histórico coevolutivo deste patossistema é relativamente recente e séries alélicas são provavelmente fruto de pressão de seleção exercida por mutações em genes complementares de virulência no patógeno após longo contato entre patógeno e hospedeiro (Bent \& Mackey, 2007). Variação em resistência a $P$. psidii também foi relatada em outros gêneros de mirtáceas provenientes de várias regiões da Austrália, indicando que não só o gênero Eucalyptus possui genes de resistência a este fungo (Zauza, 2007). Em patossistemas florestais com pouco histórico coevolutivo e onde existe resistência monogênica, como pinus $\mathrm{x}$ ferrugem e populus $\mathrm{x}$ ferrugem, a resistência é conferida por genes de resistência a patógenos similares encontrados no local de origem do hospedeiro (Devey et al., 1995; Newcombe et al., 1996) e exemplos de um mesmo gene conferindo resistência a diferentes patógenos (Cooley et al., 2000), a várias raças de um 
patógeno (Buschges et al., 1997) ou mesmo controlando a expressão de diferentes características tem sido encontrados na literatura (Llorente et al., 2005). Estes patógenos devem codificar proteínas que possuem certas regiões em comum, que possivelmente desempenham papel indispensável à sua sobrevivência, permitindo assim que a proteína de resistência do hospedeiro reconheça diferentes proteínas de avirulência do patógeno.

Desta forma, é possível que o loco detectado neste estudo, a exemplo do discutido acima também confira resistência a vários isolados/raças do patógeno ou mesmo a outros patógenos geneticamente relacionados encontrados no centro de origem do eucalipto. De fato, um loco de resistência à ferrugem foi mapeado em várias famílias segregantes no grupo de ligação 3 do mapa de referencia de eucalipto (Bueno et al., 2004; Rosado, 2007; Alves, 2008), onde um QTL de resistência a Mycosphaerella também foi mapeado neste mesmo grupo de ligação (Freeman et al., 2008), o que sugere a existência de um loco de resistência que atue contra mais de um patógeno.

\section{AGRADECIMENTOS}

Os autores agradecem o apoio financeiro da Votorantim Celulose e Papel - VCP, bem como aos técnicos do programa de melhoramento que auxiliaram nos experimentos. Ao Conselho Nacional de Desenvolvimento Científico e Tecnológico - CNPq pela concessão da bolsa de doutorado do primeiro autor e à Coordenação de Aperfeiçoamento de Pessoal de Nível Superior - CAPES pelo apoio financeiro através do programa PROEX.

\section{REFERENCIAS BIBLIOGRÁFICAS}

Alfenas AC, Zauza EAV, Maffia RG, Assis TF (2004) Clonagem e Doenças do Eucalipto. $1^{\text {st }}$ Ed. Viçosa MG. Editora UFV.

Alves AA (2008) Herança e mapeamento genético da resistência a ferrugem (Puccinia psidii) em cruzamentos interespecíficos de Eucalyptus. Dissertação de Mestrado. Universidade Federal de Viçosa. Viçosa MG.

Aparecido CC, Figueiredo MB, Furtado EL (2003) Grupos de variabilidade fisiológica em populações de Puccinia psidii. Summa Phytopathologica 29:234-238.

Bent A, Mackey D (2007) Elicitors, effectors and R genes: The new paradigm and lifetime supply of questions. Annual Review of Phytopathology 45:399-436.

Bueno NW, Junghans DT, Alfenas AC, Brommonschenkel SH, Grattapaglia D (2004) Localized mapping of the Puccinia psidii resistance (Pprl) locus in Eucalyptus with microsatellite markers. Proceedings 50th. Congresso Brasileiro de Genética. Florianópolis SC GP1286.
Buschges R, Hollricher K, Panstruga R, Simons G, Wolter M, Frijters A, van Daelen R, van der Lee T, Diergaarde P, Groenendijk J, Topsch S, Vos P, Salamini F, Schulze-Lefert P (1997) The barley Mlo gene: a novel control element of plant pathogen resistance. Cell 88:695-305.

Carvalho ADO, Alfenas AC, Maffia LA, Carmo MGF (1998) Resistance of Eucalyptus species, progenies and provenances to Puccinia psidii. Pesquisa Agropecuária Brasileira 33:139-147.

Cooley MB, Pathirana S, Wu HJ, Kachroo P, Klessig DF (2000) Members of the ArabidopsisHRT/RPP8 family of resistance genes confer resistance to both viral and oomycete pathogens. Plant Cell 12:663-676.

Coutinho TA, Wingfield MJ, Alfenas AC, Crous PW (1998) Eucalyptus rust: A disease with the potential for serious international implications. Plant Disease 82:819-825.

Devey ME, Delfino-Mix A, Kinloch BB, Neale DB (1995) Random amplified polymorphic DNA markers tightly linked to a gene for resistance to white pine blister rust in sugar pine. Proceedings of the National Academy of Science USA 92:2066-2070.

Dianese JC, Haridasan N, Moraes RSA (1986) Screening Eucalyptus for rust resistance in Bahia. Tropical Pest Management 32:292-295.

Ferreira FA (1983) Ferrugem do eucalipto. Revista Árvore 7:91-109.

Freeman JS, Potts B, Vaillancourt RE (2008) Few mendelian genes underlie the quantitative response of a forest tree, Eucalyptus globulus, to a natural fungal epidemic. Genetics 178:563-571.

Furtado GQ, Castro HA, Pozza EA(2005) Variabilidade fisiológica de Puccinia psidii Winter em Eucalyptus grandis e no hibrido urograndis. Summa Phytopathologica 31:227-231.

Glen M, Alfenas AC, Zauza EAV, Wingfield MJ, Mohammed C (2007) Puccinia psidii: a threat to the Australian environment and economy - a review. Australasian Plant Pathology 36:1-16.

Junghans DT, Alfenas AC, Maffia LA (2003a) Escala de notas para a quantificação da ferrugem do eucalipto. Fitopatologia Brasileira 28:184-188.

Junghans DT, Alfenas AC, Brommonschenkel SH, Oda S, Mello EJ, Grattapaglia D (2003b) Resistance to rust (Puccinia psidii Winter) in eucalyptus: mode of inheritance and mapping of major gene with RAPD markers. Theoretical and Applied Genetics 108:175-180.

Llorente F, Alonso-Blanco C, Sanchez-Rodriguez C, Jorda L, Molina A. (2005) ERECTA receptor-like kinase and heterotrimeric $\mathrm{G}$ protein from Arabidopsis are required for resistance to the necrotrophic fungus Plectosphaerella cucumerina. Plant Journal 43:165-180.

Meksem K, Doubler TW, Chancharoenchai K, Njiti VV, Chang SJC, Rao Arelli AP, Cregan PE, Gray LE, Gibson PT, Lightfoot DA (1999) Clustering among loci underlying soybean resistance to Fusarium solani, SDS and SCN in near-isogenic lines. Theoretical and Applied Genetics 99:1131-1142.

Meyers BC, Kaushik S, Nandety RS (2005) Evolving disease resistance genes. Current Opinion in Plant Biology 8:129-134.

Newcombe G, Bradshaw Jr HD, Chastagner GA, Steller RF (1996) A major gene for resistance to Melampsora medusae f.sp. deltoidae in a hybrid poplar pedigree. Phytopathology 86:87-94.

Rosado TB (2007) Mapeamento de gene letal, responsável pela distorção de segregação e detecção de QTL para resistência a 
ferrugem (Puccinia psidii) em Eucalyptus spp. Tese de Doutorado. Universidade Federal de Viçosa. Viçosa MG.

Silveira RLVA, Higashi EN (2003) Aspectos nutricionais envolvidos na ocorrência de doenças com ênfase para o eucalipto. Circular Técnica, Instituto de Pesquisa e Estudos Florestais 200:1-13.

Telechea N, Rolfo M, Coutinho TA, Wingfield MJ (2003) Puccinia psidii on Eucalyptus globulus in Uruguay. Plant Pathology 52:427.

Zamprogno KC, Furtado EL, Marino CL, Bonine CAV, Dias DC (2008) Utilização de análise de segregantes agrupados na identificação de marcadores ligados a genes que controlam resistência à ferrugem (Puccinia psidii) em Eucalyptus spp. Summa Phytopathologica 34:253-255.

Zar JH (1996) Biostatistical Analysis. Third edition. Upper Saddle River NJ. Prentice Hall.

Zauza EAV (2007) Epidemiologia da ferrugem do eucalipto e resistência genética. Tese de Doutorado. Universidade Federal de Viçosa. Viçosa MG.

TPP 9024 - Recebido 12 Fevereiro 2009 - Aceito 21 Agosto 2009 Editor de Seção: Carlos R. Casela 